\title{
Development And Design Of A New Kind Of Grinding Equipment For Production Of Hardware
}

\author{
Zhao Zhanfeng \\ Wenzhou Vocational \& Technical College, Wenzhou. 325035 \\ Zhanfeng @qq.com
}

Keywords: Design. Hardware. Device. Location number.

\begin{abstract}
This paper analyzes a new kind of grinding equipment for production of hardware, including External working table, first working board, second working board, grinding motor, control motor and rotary motor. The center of the workbench has a dust collecting port . soleplates are installed on both sides of the workbench and a rotating motor is installed on the outboard of the soleplate. The top of the mounting seat has a rotating plate, and the output end of the rotary motor is connected to the rotary plate. This product can realize continuous operation of multiple stations through circular sliding rail to drive the work of the workbench, making the operation of the device more efficient. Structural design of the reverse part of the fixed part and annular mounting plate can be used to Improve the station number of the device to facilitate the use of the device.
\end{abstract}

\section{Technical background}

Traditional hardware products, also known as "hardware", refer to the five metals of gold, silver, copper, iron and tin, which can be made into knives, swords and other works of art or metal devices by hand. In the modern society, hardware is more extensive, such as hardware tool, hardware parts, daily hardware, building hardware and security goods etc. With the development of the market and society, hardware fittings are becoming more and more widely used, and the production demand of hardware is becoming more and more important, and hardware is the important part of hardware production.

At present, the way of polishing and the fixed way of parts of the grinding equipment of hardware are relatively simple. These devices can only be used for the grinding of a single part or a class of parts, which greatly limits the application range of the grinding equipment and has great limitation. The current grinding equipment can not select the working state of the grinding equipment according to the specific needs, and it is inconvenient to polish the irregular parts. Besides, the current grinding equipment does not have good protection and sound insulation facilities, and in the process of polishing, iron particles are splattered. At the same time, these equipments do not cooperate with the cleaning structure, resulting in the cleaning of the equipment more inconvenient .

\section{Technical Analysis}

The purpose of this product is to provide a kind of hardware for the production of hardware, in order to solve the related problems raised in the above background technology.

To achieve the above objectives, the product provides the following technical solutions: This new kind of grinding equipment for production of hardware includes external working table, first working board, second working board, grinding motor, control motor and rotary motor. The center of the workbench has a dust collecting port . soleplates are installed on both sides of the workbench and a rotating motor is installed on the outboard of the soleplate. The top of the mounting seat has a rotating plate, and the output end of the rotary motor is connected to the rotary plate. The inner part of the rotary plate is fitted with a mounting block, and the inside of the mounting block is fitted with a circular slide track. The inner side of the circular slide rail is equipped with four sets of gliders, 
and the top of the slider is mounted with a circular mounting plate. The top of the ring mounting plate has a second worksheet, and the upper part of the second job board has four sets of second slots. The intermediate position above the second job board is fitted with a u-shaped splint. A pneumatic cylinder is installed in the middle of the side wall of the u-shaped splint and a splint is installed in the output end of the pneumatic cylinder. At the bottom of the second job board, there is a first operating panel, and the bottom installation of the first job board has four sets of first placement slots. A telescopic rod is installed at the four corners above the table, and a support plate is installed on the top of the telescopic rod. An electromagnetic slide is installed in the middle of the bottom of the support plate, and an electromagnetic sliding block is installed at the bottom of the electromagnetic slide. The bottom of the electromagnetic sliding block is equipped with a support plate. The bottom of the support plate is equipped with an electric telescopic rod. The output end of the electric telescopic rod is installed with an l-type mounting bracket. A fixed plate is installed at one end of the same l-type mounting bracket, which stays away from the end of the electric telescopic rod. And a control motor is installed on the outside of a fixed plate.

The middle position of the inner part of the fixed plate is fitted with a bearing, and the bearing is connected by a rotating shaft. The middle position of the rotating shaft is installed with a mounting bracket and a grinding motor is installed at the bottom of the mounting base. The output end of the grinding motor is installed with a rotating shaft, and the installation pipe is installed on the bottom of the rotating shaft. At the bottom of the installation pipe, there is a grinding disc, and a mounting column is installed at the bottom of the grinding disc. The bottom of the mounting column is mounted with a grinding head. Besides, A u-shaped baffle is installed in the middle position above the workbench and a fan is installed on the outside of the u-shaped baffle. The inner side of the ushaped baffle is fitted with a hood, which is connected to the output end of the fan.

\section{Ergonomics analysis}

There is a diesel engine on the outside body, and the diesel engine is connected to each other through another belt and a clear gray cover. The ash cover is connected to the rotating horizontal axis. The rotating shaft is fitted with a broken barrel, and the surface of the bucket is mounted with a splint. At the same time, the broken material thorn and crushing barrels are disassembled and installed, as is shown in figure 1.

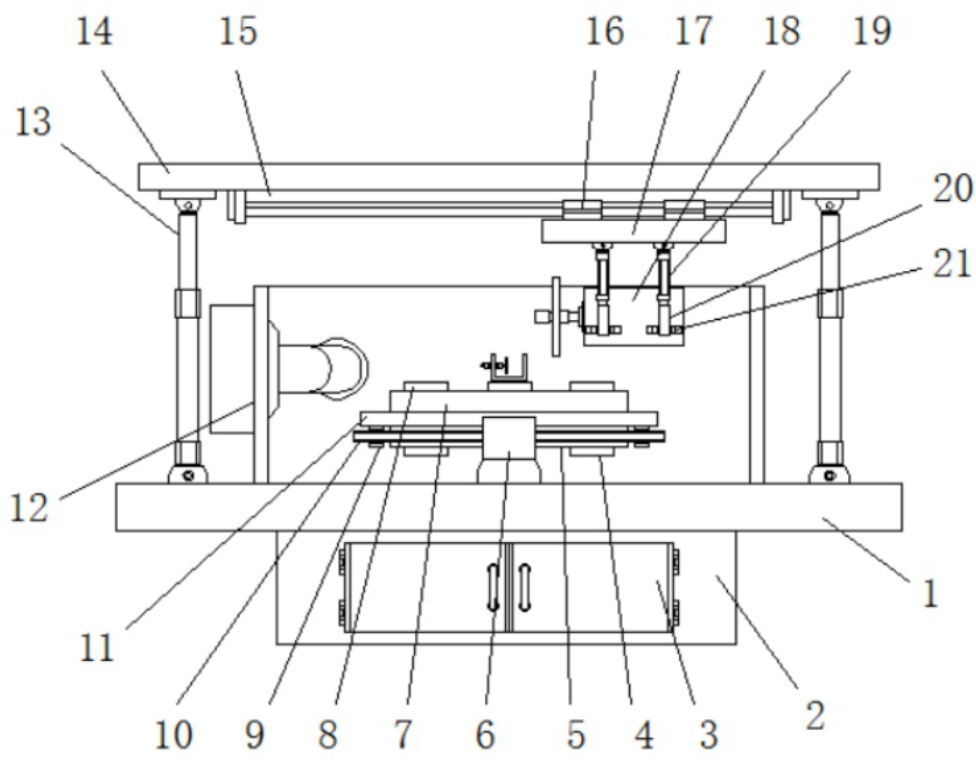

Figure 1 Workbench

The dust box is installed at the bottom of the table, and the front of the dust box is set with a clear lid. The top of the workbench is connected with the dust collecting port, as is shown in figure 2. 


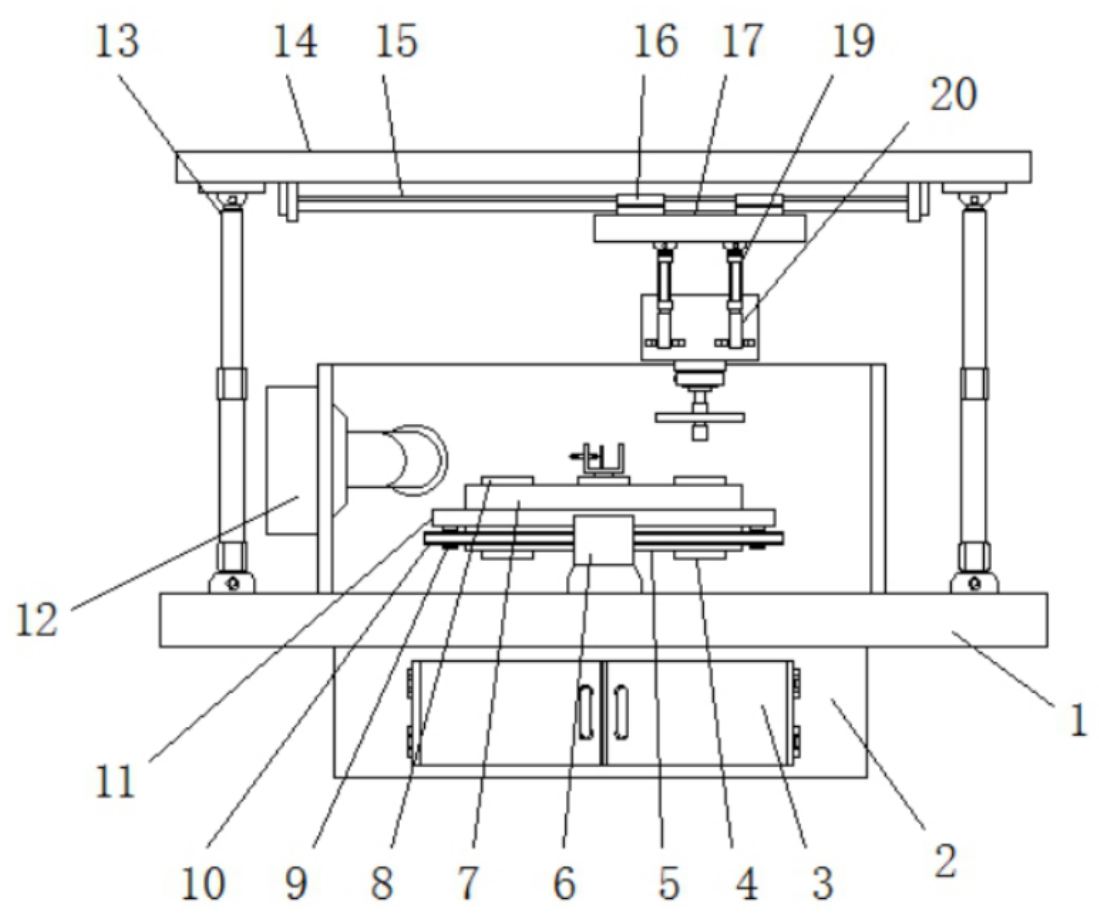

Figure 2 dust box of the workbench

There are six sets of first installation springs on the inner side of the first slot, and two sets of arc clips are arranged at the end of the first installation spring away from the inner wall of the second place. The two ends of the second place are installed with a row of second installation springs, and the second installation spring is removed from the end of the second place. Arc clamping piece and the inner side of the jaw are set with rubber pads, as is shown in figure 3.

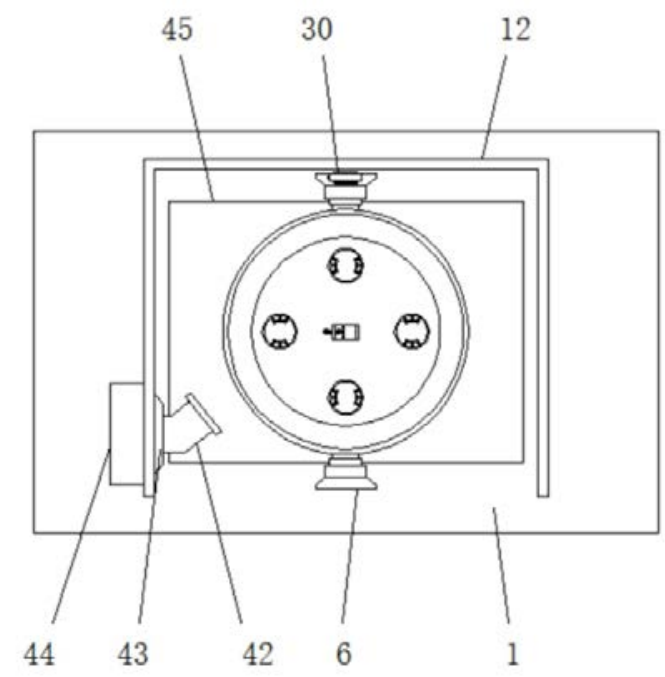

Figure 3 Rubber Blanket

The rotating shaft and the installation pipe are connected by thread. The mounting column and the grinding head are connected by a screw. There are two sets of reinforcing ribs on the side wall of L type mounting bracket. As is shown in Figure 4. 


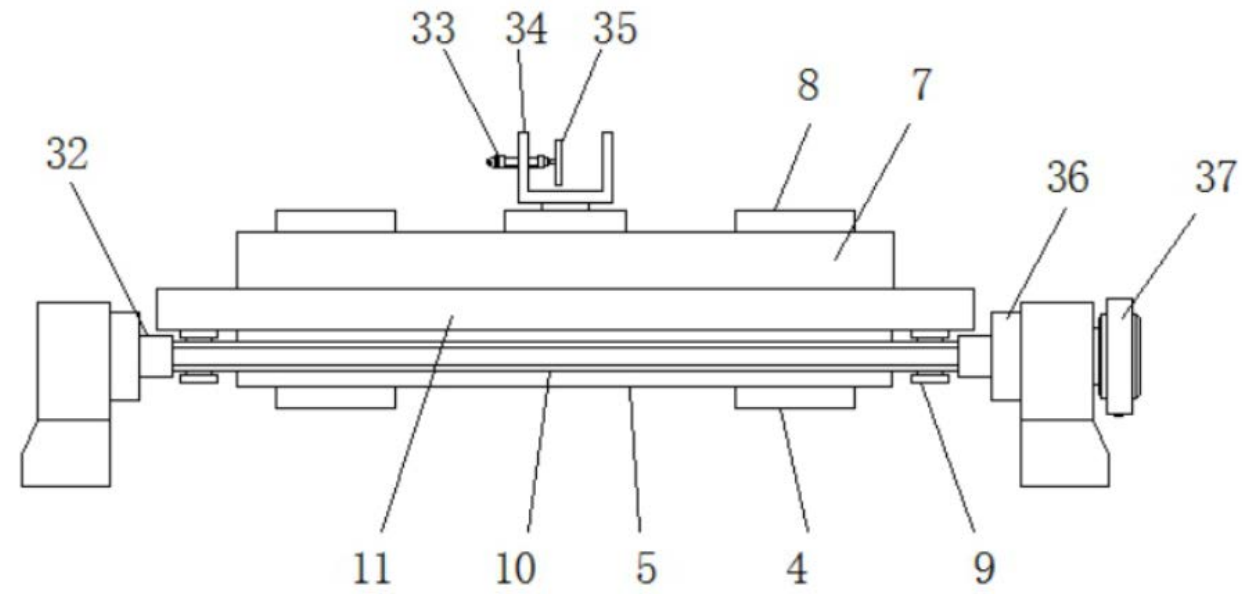

Figure 4 Dead Plate

The inside of the splint has a non-slip layer. The rotation Angle of the mounting seat is $0{ }^{\circ}$ to $90^{\circ}$. And the number of electromagnetic sliding rail is two groups, and there are two sets of electromagnetic slider on the electromagnetic slide. As is shown in Figure 5.

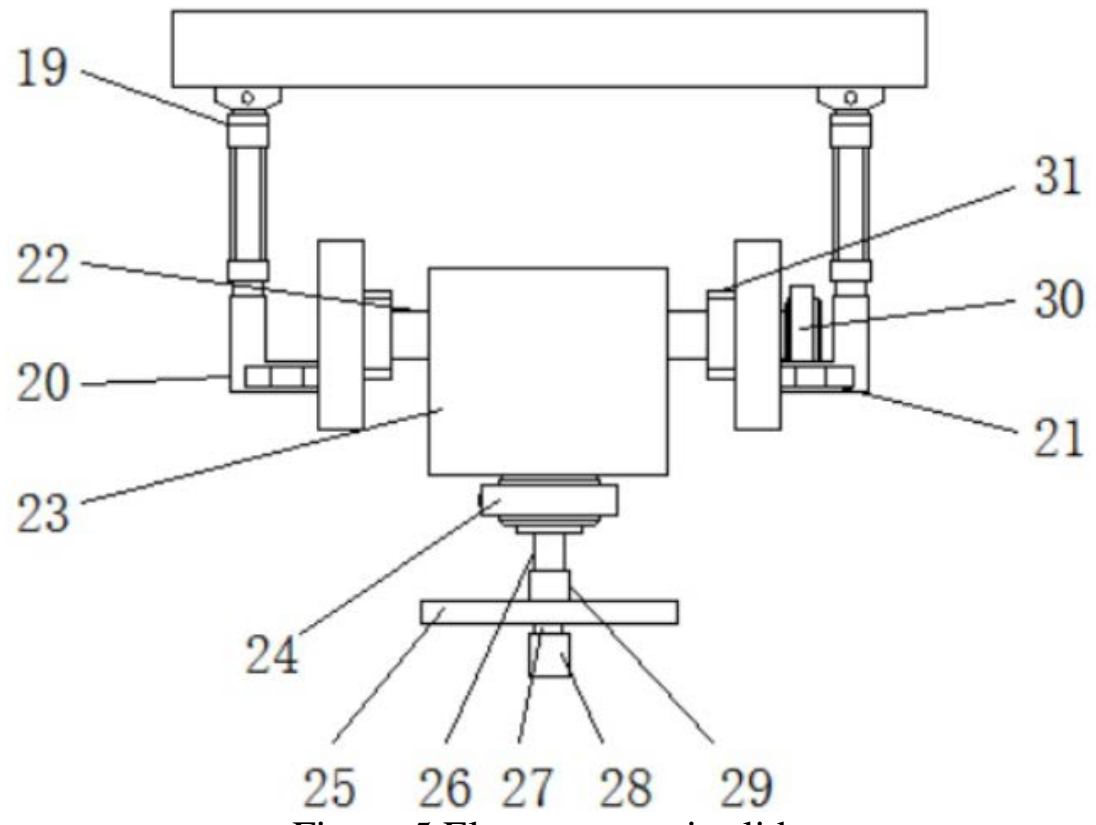

Figure 5 Electromagnetic slider

The inside of the u-shaped baffle is provided with a protective layer, and the outer part of the ushaped baffle has a soundproof layer, as is shown in figure6.
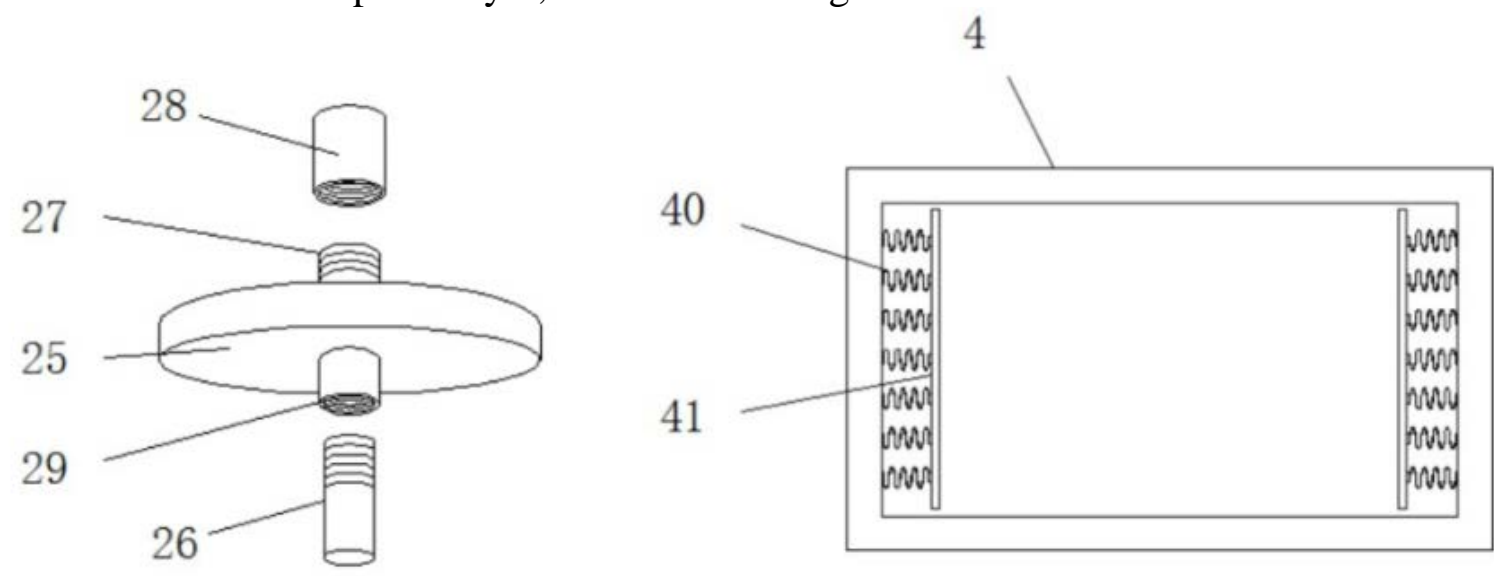

Figure 6 covering layer 


\section{Conclusion}

Compared with the existing technology, the beneficial effect of this product is: The production of the hardware is the way of grinding equipment to drive the workbench by circular sliding track, which can realize continuous operation of multiple stations, making the operation of the device more efficient. At the same time, with the structure of u-shaped splint, pneumatic cylinder and splint, the parts of different shapes can be fixed. The autobiographical and flip side of the fixed position can better polish the different parts of the parts, making the operation easier and more convenient. The device is equipped with a u-shaped baffle, which can effectively protect the staff and play a better sound insulation effect, which can reduce the noise pollution generated during the production process. The dust box at the bottom of the match can be better collected for the metal chips to facilitate the unified cleaning. At the same time, the device is equipped with a fan, which can not only play a certain cooling role in the operation, but also can blow the metal dust into the dust collecting box, making the cleaning of the device more convenient.

\section{References}

[1]LI Jun-hua. Emotional Expression in the Product De-sign[J]. Packaging Engineering, 2010, 31(2): 32-35.

[2]MA Ze-qun, GOU Rui, HUANG Qiang-ling. Dilemma and Strategy o the Bionic in Design the Ndustria Design Fied[J]. Packaging Engineering, 2013, 34(20): 111 -113.

[3]TIAN Jun. Natural Source and Direction: Luigi Colani's Bionic Design[J]. Zhuangshi, 2013(4): $35-40$.

[4]LIU Guan-zhong. The Important Task of China's In $\square$ dustrial Design[J]. Design,2015(22): 150— 152.

[5]LIU Guan-zhong. Design: The Third Wisdom to Save Humans from Destruction[J]. Design Research, 2011,1(1): 5-8.

[6]FISK A D. Designing for Older Adults: Principles and Creative Human Factors Approaches[M]. Boca Raton: CRC Press, 2004. 